\title{
Matto de Turner: indio y novela del $\mathrm{XIX} *$
}

\section{MILAGROS CARAZAS SALCEDO}

A partir de los años 70 la crítica literaria peruana se bifurca en dos tendencias contrapuestas, sin que esto anule la existencia de una posición intermedia. La primera tendencia opta por una línea de pensamiento cercana a la problemática literaria nacional, tratando de plantear los aspectos más relevantes de nuestra tradición literaria desde una perspectiva social e histórica como lo hacen Antonio Cornejo Polar, Tomás Escajadillo y Alejandro Losada. En cambio, la segunda, incorpora y divulga las nuevas corrientes formalistas y neopositivistas de la crítica literaria europea, en especial, la semiótica y el postestructuralismo tal como lo atestiguan los trabajos de Enrique Ballón, Desiderio Blanco y Susana Reisz. Por otro lado, en una tercera posición intermedia que une elementos de ambas tendencias tenemos a críticos como EdmuhalolBendezu, Raúl BuenoSy Julio Ortega.

En la primera, la tendencia sociológica, destäcamos al renombrado crítico peruano Antonio Cornejo Polar (n. Lima, 1936), tanto por su labor directriz (ex-rector de la Universidad de San Marcos y actual director de la Revista Crítica Literaria Latinoamericana) y académica (Profesor Emérito de la Universidad de San Marcos y actual profesor en la Universidad de Pittsburgh-USA), como también por sus numerosos estudios y libros, es decir, nos referimos a Edición y estudio del "Discurso en loor de la poesía" (1964) en torno al texto colonial de Clorinda; Los universos narrativos de José María Arguedas (1973) donde se aborda la narrativa de este escritor peruano; La novela peruana; siete estudios (1977) que reune trabajos sobre Alegría, Arguedas, López

* Antonio Cornejo Polar. Clorinda Matto de Turner, novelista. Lima, Lluvia editores, 1992, 97 p. 
Albújar, Matto de Turner y Ribeyro; Literatura y sociedad en el Perú: la novela indigenista (1980) que partiendo de la tesis de Mariátegui replantea el problema nacional en la literatura peruana; Sobre literatura y crítica latinoamericana (1982) una reflexión sobre la materia; Nuevo cuento peruano (1984) donde es compilador al lado de Fernando Vidal; y La formación de la tradición literaria en el Perú (1989) donde vuelve sobre la pluralidad básica de la literatura peruana, aplicando su categoría de heterogeneidad.

A esta copiosa producción debemos añadir ahora su libro Clorinda Matto de Turner, novelista (1992), una colección de cinco estudios sobre las tres novelas de la escritora cuzqueña Clorinda Matto (1852-1909), es decir, Aves sin nido (1889), Indole (1891) y Herencia (1895), dejando de lado Tradiciones, leyendas y hojas sueltas (1883), que fuera editado por Peisa bajo el título de Tradiciones cuzqueñas completas (1976), y además su producción periodística publicada en revistas como Ateneo, Círculo Literario, y El Perú Ilustrado la que dirigió en 1889.

Cornejo Polar inicia su libro con un breve prólogo, donde juzga que los estudios reunidos en este "pequeño volumen" son los más útiles para el lector, ofreciêndole un panorama de la novelística de Clorinda Matto. Como él lo indica, estos estudios ya han sido publicados anteriormentę ể diferentes dibrōs $Q$ treyistas entre 1974 y 1977 , y sólo uno es de 19990 No ta querido revisarlos,ni modificarlos porque considera que el trabajo intelectual tiene su propia historia, por lo que es arriesgado tratar de actualizar un trabajo que se hizo hace muchos años atrás. Del mismo modo, el autor sigue convencido de la importancia de la obra de Clorinda Matto en la literatura peruana. En todo caso, hubiese sido preferible presentar estos estudios en orden cronológico a su publicación, para entonces apreciar el desarrollo intelectual al que se alude.

Así nos introducimos al tema con "Clorinda Matto de Turner: para una imagen de la novela peruana del Siglo XIX". El autor desarrolla el sistema narrativo de las novelas de Clorinda Matto, para en seguida proponer algunos rasgos de la novela peruana de este siglo. Este sistema se basa en un doble nivel discursivo: representación y tesis. En el nivel de representación se muestra un referente determinado (la vida en los villorrios, la hacienda de la Sierra peruana o la vida en 304 
Lima), para luego postular un juicio de valor o una reflexión que intenta explicar las realidades presentadas. Mientras que en el nivel de la tesis se pretende convencer a los lectores de la validez de ciertas ideas morales (el rechazo al celibato sacerdotal, la inconveniencia de la confesión de la mujer casada y el cuestionamiento al sacramento de la penitencia, y la influencia del legado hereditario y el medio ambiente), lo que revelaría una perspectiva ética. La bimembración del sistema narrativo es la base del análisis de Cornejo Polar, lo usa como plantilla aplicable a las tres novelas de Clorinda Matto, a éste vuelve reiteradamente para dar cuenta también de las particularidades de la novela peruana del s. XIX, como puede observarse en los subsiguientes trabajos.

En "Aves sin nido: indios, "notables" y forasteros" Cornejo Polar describe el mundo representado de esta novela. Entonces se destacan dos espacios: Kíllac, símbolo de los villorrios serranos, y Lima, sede idealizada de la civilización. En el primero se desenvuelve una negativa vida social que contrapone dos clasés: los inmorales "notables" que asumen los cargos del poder político, judicial o eclesiástico, y los explotados indios representados por la familia de Juan Yupanqui e Isidro Champi. A estos dos grupos sociales se relacionan los forasteros asumidos por la familia Marín, quienes se oponen a los primeros y defienden a los últimos. De acuerdola CornejaSPolar, el verdadero significado social de Ävesssin midoirsabiaccenen la historia amorosa de Manuel y Margarita, y es que a través de la educación de los indios y "notables" de la Sierra pueden acceder al mundo de los forasteros. Pero también hallamos el tema religioso a manera de censura del celibato, pues son dos los sacerdotes que intervienen en esta novela: el recuerdo del cura Miranda y Claros, padre de Manuel y Margarita, y el cura Pascual Vargas, lleno de vicios. Sin embargo, Cornejo Polar señala que el mundo andino representado tiene algunas limitaciones que responden al desarrollo de la conciencia nacional del siglo pasado.

Más adelante, en "Aves sin nido como alegoría nacional", se hace una reflexión sobre la modernidad, una de las preocupaciones de la sociedad peruana del s. xIx. Tras la Guerra del Pacífico la nación buscaba alternativas a la crisis que se había sumido, en estas circunstancias aparece la figura de González Prada, el principal portavoz 
modernizador para el país, capaz de rescatar al pueblo indígena por medio de la educación, siendo sus principales ejecutores los jóvenes. Estas ideas influyeron en Clorinda Matto, así en Aves sin nido leemos que las hijas de Juan y Marcela Yupanqui (Margarita y Rosalía) son adoptadas por los Marín, a esta nueva identidad le sigue después un proceso educativo, en otras palabras, la salvación del indio depende de su conversión en otro, en criollo. Por otro lado, la constitución inter-racial de la familia Marín expresa el deseo de una nación homogénea, sentimiento que responde a las preocupaciones nacionales del XIX: el problema de la desintegración nacional impedía el progreso. Para Cornejo Polar, entonces, el mensaje de esta novela se reduce a demostrar que la homogeneidad étnica es una necesidad nacional para integrar los indios a la vida republicana.

Los dos últimos estudios corresponden a las novelas menos difundidas de Clorinda Matto. Cornejo Polar intenta reflexionar sobre "Lo social y lo religioso en Indole". La historia de las familias de Don Antonio y Don Valetín, y de Ildefonso y Ziska, se desenvuelven en dos espacios: el pequeño pueblo de Rosalinda y la hacienda de $\mathrm{Pa}$ lomares. La actitud narrativa es otra, aparece en esta novela la "observación fisiológica-moral", es decir, se quiere "detectar la naturaleza psicofísica del comportamiento humano, en relación... [al] medio ambiente... y ...explicarostus caracteres y àsenir en términos de objetividad científicarg(p. 77 ). 9 Asi 9 a realidad social representada tiene los siguientes estratos: en el primero, encontramos a los vecinos ricos, de un lado a Antonio y Eulalia, personajes débiles y poseedores de buena índole, y del otro Valentín y Asunción, cuya caracterización es negativa; el segundo, lo conforman los humildes mestizos como Ildefonso y Ziska; y el último estrato social lo conforman los indios, atrapados por la injusticia y la explotación. Según parece esta vez la crítica se orienta a la vida provinciana, en especial, de los vecinos poderosos como el deshonesto Don Valentín. En otro extremo encontramos nuevamente el tema religioso, la historia del cura Peñas, obsesionado sexualmente por doña Eulalia y confesor de doña Asunción, revela la intención crítica de Indole, la censura al celibato y a la confesión. Para el autor esto reafirma que Clorinda Matto percibía la novela como "un instrumento de la moral social destinado a combatir 
los vicios de una sociedad que consideraba enferma y desviada" (p. 89).

"Sobre Herencia" es un brevísimo estudio donde Cornejo Polar resalta otra vez la organización bimembre de las novelas de Clorinda Matto. La familia Marín de Aves sin nido reaparece aquí, para oponerse a la frívola familia Aguilera, ambas actúan dentro del ambiente limeño. Herencia es una novela que pone en primer plano el legado hereditario, donde lo fisiológico es superado por la influencia del medio y por elementos de orden espiritual y educativo; de este modo las vidas de Margarita Marín y de Camila Aguilera responden a fuerzas mayores, por eso Cornejo Polar considera que ésta es una novela que sigue el modelo naturalista como lo sostiene Clorinda Matto: "[la novela] copia y no inventa" (p. 97).

Clorinda Matto de Turner, novelista es un libro que no sólo introduce al lector al tema, sino que además da pautas para comprender mejor la heterogénea novela del s. xIx. Elanálisis de Cornejo Polar es encomiable porque va más allá de Aves sin nido, deteniéndose con éxito en las otras dos novelas de Clorinda Matto, pero ofreciendo un panorama relativamente completo de la producción de la escritora cuzqueña ya que descarta el resto de sus trabajos. Sin embargo, el esfuerzo es válido y abreccamino para posteriores investigaciones en el mismo tema. «Jorge Puccinelli Converso» 